\title{
Alternativa de intervenção social para o estágio supervisionado: Minicursos em questão
}

Isaíde Bandeira Timbót

\section{RESUMO}

Este artigo propõe uma reflexão sobre o Estágio Supervisionado e o Ensino de História. Tendo como pressuposto o trabalho com projetos de minicursos, visto como uma intervenção sócio-pedagógica concreta no cotidiano escolar e na formação docente do historiador-educador. Nesta perspectiva viabiliza ainda a extensão universitária, através de uma relação dialógica entre Universidade e diferentes escolas da comunidade.

Palavras-chave: Formação docente, Estágio Supervisionado, Ensino de História.

No processo de formação docente dos futuros historiadores-educadores (FONSECA, 2003), principalmente nas disciplinas relacionadas ao Estágio Supervisionado, é mister indagar: "Como é registrada, escrita e transmitida a História na educação básica?"; "Os projetos de trabalho podem influenciar na melhoria da prática educacional histórica?; "Como desenvolver Projetos de Trabalho no Ensino de História?".

Este debate requer uma rearticulação com os conteúdos estabelecidos e, quando possível, a superação da ordem cristalizada destes, no processo constante da disputa, como diz Michel de Certeau, entre táticas e estratégias, pois há "maneiras de fazer" (CERTEAU, 1994, pp. 41 e 92) que alteram ou reinventam formas de viver no espaço organizado e pré-fixado, num fazer diferente dentro do oficial.

Assim faz lembrar os projetos de trabalho em cuja concepção predominam a atitude de inovação e a cooperação, sendo o professor não um especialista que dá

1 Professora das disciplinas Prática de Ensino e Didática do Ensino de História do curso de História da Universidade Estadual do Ceará. 
respostas prontas e acabadas, pelo contrário é aquele que favorece a busca conjunta de respostas para os problemas elaborados norteadores da prática.

Para HERNÁNDEZ, o professor é de fato um aprendiz "diante do processo a seguir e das maneiras de abordá-lo, que nunca se repetem, que sempre adquirem dimensões novas em cada grupo." $(1998$, p.83) Segundo esse autor, uma das grande dificuldades de se trabalhar com projetos é não se estar preparado para viabilizar um ensino que favoreça uma intervenção na realidade social. $^{2}$

Nesta perspectiva, como pensar o Estágio Supervisionado para além da burocracia (que o torna quase indesejável para a maioria dos alunos), e possa de fato contribuir para a formação docente dos futuros historiadores-educadores? É possível, a partir do Estágio Supervisionado, favorecer o "chão da sala de aula" das escolas que recebem os estagiários?

Para melhor responder a estas questões, é preciso entender a escola como um espaço social e inserida na sociedade, não podendo a educação formal, de modo especial a disciplina História, se furtar das transformações que se processam no cotidiano. De acordo com Michel APLLE (1989), a escola tem duplo papel: reprodutora da ideologia dominante por um lado e por outro pode estimular lutas contra as injustiças, mediante projetos alternativos de ensino, com prática pedagógicas inovadoras a partir de uma concepção educacional que se contraponha à pedagogia tradicional e favoreça o pensamento crítico.

A idéia de trabalhar com minicurso no Estágio Supervisionado é uma oportunidade para lidar com projeto que “...potencializa o desenvolvimento de estudos e pesquisas, numa perspectiva inter e multidisciplinar..."(FONSECA, 2003, p. 116), tendo em vista uma nova concepção teórico-metodológica na construção do conhecimento histórico, que não se limita à definição de conceitos e técnicas de ensino, mas favorece um fazer diferente no Ensino de História, a partir de um processo reflexivo em constante transformação. É, portanto, uma intervenção concreta no cotidiano escolar de inúmeros alunos que, em geral, pela primeira vez, têm a chance de participar de uma curso extracurricular.

A proposta de se trabalhar com minicurso no Estágio Supervisionado foi primeiramente pensada pela professora Maria Socorro Lucena LIMA (2001),

\footnotetext{
2 De acordo com Paulo Freire "a educação é uma forma de intervenção no mundo". (Cf.; FREIRE, 1996).

3 Faculdade de Ciências e Letras do Sertão Central - campus da Universidade Estadual do Ceará, localizado em Quixadá/Ceará.
} 
no início dos anos de 1990, no curso de Pedagogia da FECLESC ${ }^{3}$, e se popularizou entre as diferentes licenciaturas da UECE. E pauta-se na sua essência na pedagogia de projetos, na "relação entre o saber das disciplinas, 0 conhecimento escolar e a função social da escola" (HERNÁNDEZ, 1998, p. 66), em que predomina a cooperação de todos os envolvidos na busca de um fazer diferente e, para lembrar Gonzaguinha, "cantar a beleza de ser um eterno aprendiz."

O curso de História da UECE, ainda sob vigência do currículo aprovado em 1992, oferta nos dois últimos semestres da licenciatura duas disciplinas de Prática de Ensino em História (I destinada ao Ensino Fundamental e II para 0 Ensino Médio), com carga horária de 120 h/a cada uma, muito similar ao esquema 3+1 imposto com a Reforma Universitária (Lei 5540/68) em que se vê três anos da disciplina de conteúdo específico da área e um ano das disciplinas ditas pedagógicas. Esta realidade, contudo, está mudando, pois já foi aprovado $^{14}$, pelo Conselho de Ensino, Pesquisa e Extensão (CEPE) da UECE, a Reforma Curricular do Curso de História.

Socializar a condução das disciplinas de Prática de Ensino I e II de História, do curso de Licenciatura Plena em História da UECE, por meio de minicurso, constitui uma satisfação de apresentar para a crítica a aplicação de uma experiência que vem dando certo, no intuito de ampliá-la e melhorá-la.

Quando comecei com a proposta de minicursos como professora das disciplinas Prática de Ensino I e II, escolhia junto com os alunos uma escola-pólo para ser o espaço de todos os minicursos, que se realizavam somente aos sábados para termos acesso ao número de salas necessárias e ainda favorecer o processo de

\footnotetext{
0 novo Projeto Político Pedagógico do Curso de História da UECE começou a ser debatido em abril de 2001 por uma comissão de oito professores do curso, tendo em vista a Resolução do Conselho Nacional de Educação/Conselho Pleno n. 02 de 19 de fevereiro de 2002, o qual determina $400 \mathrm{~h} /$ a para Estágio Curricular Supervisionado. Sendo assim, a Comissão de Reforma Curricular junto ao Colegiado do Curso, após várias reuniões, permeadas de reflexões e debates, decidiu distribuir esta carga-horária em cinco disciplinas diretamente ligadas ao Ensino de História e a realidade escolar, fato que deu uma nova consistência ao processo de formação docente do historiador-educador: Foi aprovado em 10 de dezembro de 2003 no Conselho de Ensino, Pesquisa e Extensão (CEPE). Assim os ingressos no curso de História da UECE a partir do primeiro semestre de 2004 terão a oportunidade de cursar as seguintes disciplinas da área de Ensino de História: Metodologia do Ensino de História ( $4^{\circ}$ semestre - $60 \mathrm{~h} / \mathrm{a}$ ); Oficina de Instrumentos didáticos $\left(5^{\circ}\right.$ semestre - $60 \mathrm{~h} / \mathrm{a})$; Educação Patrimonial $\left(6^{\circ}\right.$ semestre - $\left.90 \mathrm{~h} / \mathrm{a}\right)$; Prática de Ensino I ( $7^{\circ}$ semestre - $90 \mathrm{~h} /$ ) e Prática de Ensino II ( $8^{\circ}$ semestre - $\left.120 \mathrm{~h} / \mathrm{a}\right)$.
} 
acompanhamento de minha parte como supervisão dos trabalhos desenvolvidos pelas equipes de estagiários. Por dois semestres, no entanto, percebi que as escolas escolhidas para serem o que chamo de pólo ficavam no centro da Cidade e o corpo discente em geral não tinha condição de pagar condução para participar dos minicursos aos sábados e outros não se empolgavam com a idéia de terem que "dispensar" seu final de semana. Assim, decidi junto com os estagiários dos semestres seguintes descentralizar a ação e fazer da disciplina uma oportunidade de tornar concreto o terceiro pilar da Universidade: a extensão, no diferentes bairros de Fortaleza, inclusive na periferia.

Os minicursos constituem-se, então, uma parceria entre Universidade e escola, em que os estagiários oferecem algo, como um período de informação, reflexão, compreensão e debate sobre um fato histórico, e recebem o "desafio" de experienciar a realidade da sala de aula, que requer muito mais do que o conhecimento dos conteúdos. Faz-se necessária uma série de habilidades para viabilizar o ensinoaprendizagem, como a postura teórica, a metodologia diretamente relacionada ao domínio de sala, a respeitabilidade (sem fazer uso do autoritarismo), a relação professoi-aluno, dentre outras, tendo em vista favorecer os princíios propostos nos Parâmetros Curriculares Nacionais (BRASIL, 1999, p. 21), ou seja: aprender a conhecer; aprender a fazer; aprender a conviver e aprender a ser.

Alguns estagiários chegam às disciplinas de Estágio Supervisionado como se tivessem que carregar um fardo muito pesado, já que estas disciplinas se efetivam, em geral, apenas no último ano do curso, por exemplo na UECE concomitante com a disciplina Prática de Pesquisa - a Monografia - 0 que os deixa, sem dúvida, sobrecarregados, ainda com 0 agravante de considerarem estas e outras disciplinas ditas pedagógicas "perda de tempo" para o futuro historiador-educador, já que poucos reconhecem que o seu campo principal de trabalho, após concluírem o curso, será o ensino de História na educação básica nas diferentes escolas, sejam elas públicas ou particulares.

Uma série de fatores colaboram para que o estágio por meio de minicursos seja uma alternativa favorável na formação docente, por exemplo, rompe com a idéia do "velho" estágio, em que os estagiários precisam da permissão de um professor regente para acompanhar suas aulas por semanas no âmbito da observação, participação e regência. Este fato, na maioria das vezes, ocasiona uma situação constrangedora tanto para o professor- regente quanto para 0 
estagiário; aquele, por se sentir, na maioria das vezes, vigiado, e este por se sentir um intruso. Nessa situação, o estagiário é um ser estranho ao espaço, pois fica lá atrás anotando nas fichas de acompanhamento quase tudo o que se fala e acontece na sala de aula, além de chamar, sem o querer, a atenção dos alunos da escola, ainda correndo o risco de assumir antes do tempo a regência integral da sala de aula, pois, em geral, não tem coragem para dizer não ao professor-regente que solicita sua ajuda, por exemplo, para resolver problemas de saúde, e afirma que a sala estará bem acompanhada!

A idéia dos minicursos, portanto, supera a perspectiva de ir ao locus escolar para "sugar" algo e nada deixar em troca, pois supõe troca de experiências e construção de saberes. Por isso, chamo de intervenção social, não só da parte dos estagiários na esfera escolar, como também há intervenção dos alunos da escola e da sua própria dinâmica na formação dos futuros historiadores-educadores.

Trabalhar com minicursos exige um rigoroso planejamento dos passos a serem dados no decorrer da disciplina Prática de Ensino. No primeiro semestre de 2004, tivemos encontros, em sala de aula/UECE, duas vezes por semana, 4 h/a por dia.

No primeiro mês da disciplina, discutimos textos referentes ao Ensino de História, oportunidade que a maioria dos estagiários teve para se inteirar das mais recentes discussões desta área da Ciência Histórica : o Ensino de História.

No mês seguinte, as turmas de Prática de Ensino se dividiram em equipes (dupla ou trio) e cada uma escolheu uma escola pública ${ }^{4}$ para vivenciar a experiência de seu Estágio Supervisionado. E a primeira fase do estágio é o período que chamo de "observação participante"(CRUZ NETO, 1994), que se trata de uma espécie de sondagem de $20 \mathrm{~h} / \mathrm{a}$ da realidade do locus escolar. Isto exige do estagiário visão atenta para todos os detalhes que compõem a realidade de uma instituição educacional como a escola.

0 primeiro contato oficial com as escolas foi feito por intermédio de um ofício expedido pela Coordenação do Curso, pois as equipes já haviam visitado os

\footnotetext{
Vale dizer se privilegiou a rede pública por considerar mais coerente com princípios educacionais. Já que se faz parte de uma Universidade Pública, e o intuito não é só ir até ao espaço da escola e "sugar" o que há de melhor, que favoreça o processo de formação docente, mas dar também um retorno (por exemplo, oferecendo um curso - embora tão rápido - na área histórica) para a comunidade mais necessitada que colabora, com seus impostos, com o custo da educação superior "gratuita".
} 
estabelecimentos para saber se aceitavam estagiários e pegaram os dados da escola e da direção. Com o aval dos núcleos gestores das escolas, os estagiários passaram duas semanas acompanhando os trabalhos da disciplina História, junto ao professorregente, oportunidade de fazer um contato direto também com os alunos do ensino básico e indagar sobre sugestões de assuntos ligados à História que eles gostariam que fossem trabalhados posteriormente ali através de minicurso.

Nesse período, visitei algumas escolas onde os estagiários estavam, para conhecê-las e pedir apoio ao trabalho dos estagiários, além de perceber de perto o tipo de receptividade dada aos futuros historiadores-educadores e a proposta de minicurso. É importante ressaltar que, com relação às questões estruturais das instituições educacionais, percebi que a maioria das escolas tem um bom espaço físico, porém, com raras exceções, são malconservadas, como os muros e paredes das salas sujas, cadeiras quebradas e tumultuadas em um canto e pouca iluminação.

No terceiro mês, houve um momento de socialização das experiências do Estágio de Observação Participante, quando pude perceber as diferentes realidades que permeiam as escolas públicas de Fortaleza, algumas das quais com excelente infra-estrutura, organizadas e aptas à promoção de uma educação formal consistente, enquanto outras passam por sérios problemas desde a estrutura à disciplina. É como bem destaca uma equipe de estagiário no seu dossiê: "A falta de iluminação adequada nas áreas externas e internas das escola prejudica por demais a visibilidade dos funcionários responsáveis pela segurança..." No decorrer do debate reflexivo chegou-se à conclusão de que 0 trabalho desenvolvido pela gestão da escola influencia diretamente no desempenho do professor e dos alunos em sala de aula, pois se esta se faz presente e oferece apoio constante às atividades educacionais, a escola tem uma certa respeitabilidade e reconhecimento da comunidade discente e docente em geral.

Após o período da "observação participante" na escola, cada equipe fez um relato da experiência vivida no locus escolar. A percepção transformada em palavras demonstrou, com frequiência, o quanto a formação docente do futuros historiadores-educadores foi enriquecida por esta vivência na escola e, de modo especial, na sala de aula, como é possivel perceber no seguinte comentário feito por uma equipe: 
... aprendemos que para se ministrar uma boa aula, é preciso que haja habilidade e improviso, quando necessário, por parte do professor em ação. Ele, às vezes terá que usar a criatividade para fazer com o que o aluno não se contenha apenas com o conteúdo que lhe foi transmitido, mas tenha vontade de pesquisar para conhecer mais... (Equipe da Escola Anísio Teixeira)

Em geral, as necessidades percebidas dizem respeito à carência de inovação teórica-metodológica que favoreça ir além da voz, lousa, giz/pincel, apagador e, quando muito, o livro didático. Outra reivindicação é atinente à História local que quase inexiste no programa curricular do Ensino Fundamental II ( $5^{\mathrm{a}}$ a $8^{\mathrm{a}}$ séries) e no Ensino Médio. Assim, tanto os alunos como os professores sentem esta carência e logo solicitam aos estagiários que desenvolvam nos minicursos algo relacionado a esta problemática.

De acordo com a área da disciplina História, considerando as sugestões dos alunos e professores, cada equipe escolheu um tema para elaborar um projeto de minicurso. Cada equipe teve $20 \mathrm{~h} / \mathrm{a}$ para elaborar seu projeto. Solicitei que os projetos seguissem as normas da Associação Brasileira de Normas Técnicas, haja vista ser um trabalho acadêmico, considerando as indicações gerais, como: Identificação -"Para quem"?; Justificativa-"Por quê"?; Objetivos"Para quê"?; Conteúdos-"0 quê"?; Metodologia/Recursos-"Como"? "Com quê"?; Cronograma-"Quando"?; Avaliação-"Como avaliar"?; Referências bibliográficas - "Baseado em quem"?.

Durante a elaboração dos projetos, fiz o necessário acompanhamento de cada equipe, dando sugestões de leituras, filmes, documentários, músicas, dinâmicas, que os favorecessem no aspecto teórico-metodológico e substanciassem 0 desenvolvimento das temáticas dos minicursos em sala de aula. Ressaltei a necessidade de um posicionamento docente, conforme salienta Selva FONSECA, que favoreça "práticas pedagógicas que estimulem o debate, a investigação e a criação" (FONSECA, 2003, p. 39), que utilize, sempre que possível, diferentes fontes e linguagens, para romper com abordagens cristalizadas de História, já que hoje é inegável que o uso de diferentes linguagens (escritas, visuais, audiovisuais etc) e variadas fontes (literatura, documentos judiciais, imprensa periódica, poemas e crônicas, iconografias, monumentos, canções, filmes, depoimentos etc) tornam o ensino-aprendizagem de História (e de outras disciplinas) mais rico, numa perspectiva interdisciplinar, dinâmica 
e flexível, que favorece a percepção de fato sob vários aspectos e a compreensão para elaborar outras Histórias.

Depois foi feita, em sala de aula na UECE, uma apresentação geral de todos os projetos a serem desenvolvidos, e, como todo bom planejamento é flexível, as sugestões indicadas pelos demais colegas de turma foram, em geral, incorporadas aos projetos.

Em seguida, as equipes voltaram às escolas escolhidas e fizeram a apresentação dos projetos às suas coordenações pedagógicas, também aberto às outras possíveis sugestões, e divulgaram nas salas o período de inscrição e execução dos minicursos. Em cada minicurso foram atendidos no mínimo 20 alunos e no máximo 40.

No último mês da disciplina, foram realizados os diferentes minicursos, com carga horária de $20 \mathrm{~h} / \mathrm{a}$ cada um. Uma "gota" de Universidade na extensa periferia da cidade de Fortaleza! Momento de pôr em prática uma série de habilidades adquiridas no decorrer do cursos de licenciatura e de modo especial nos primeiros meses da disciplina Prática de Ensino. Foi a hora da culminância do que acredito ser uma intervenção social, ou seja, colaborar de forma efetiva, embora ainda mínima, para uma ação diferente no Ensino de História, de acordo com uma concepção de Educaçãa e História que considera a necessidade de despertar para um pensamento crítico-reflexivo de muitas crianças, adolescentes, jovens e adultos; momento em que sementes históricas foram lançadas, tendo em vista ações diferenciadas na sociedade, como exemplo, o conhecimento e preservaçã̃o do patrimônio histórico, já que a maioria dos minicursos diz respeito à História local.

Cada estagiário (apesar de ser um trabalho em equipe), no decorrer do minicurso, assume sua responsabilidade de se posicionar frente ao processo de ensino e aprendizagem, tendo que lidar com a chamada "arte de ensinar" e a "relação professor-aluno" como sendo os aspectos fundamentais na constituição de ser educador.

Ao final de cada minicurso todos os participantes, os alunos das escolas e estagiários, receberam os certificados ${ }^{5}$ que comprovam uma rica experiência construída em parceria: Universidade e Escola/Estagiários e alunos da educação básica.

\footnotetext{
5 Para os alunos participantes os certificados são de $20 \mathrm{~h} / \mathrm{a}$, e para os estagiários são de $40 \mathrm{~h} / \mathrm{a}$, pois é considerado o período de elaboração dos projetos.
} 
Logo após o período reservado aos minicursos, retornou-se para a sala de aula da UECE, onde cada equipe entregou e socializou um dossiê, ou seja, um material contendo todos os documentos produzidos no decorrer da disciplina Prática de Ensino, como: 0 relato de experiência da "Observação Participante" na escola; o projeto do minicurso; exemplos de trabalhos desenvolvidos junto aos participantes dos minicursos; uma reflexão escrita (individual) de cada estagiário da experiência vivida durante a realização do projeto de intervenção social na escola; e anexos (textos, letras de músicas trabalhas, fotos etc).

A interação dos estagiários e alunos das escolas foi ressaltada, na maioria dos dossiês das equipes, como um fator resultante de uma ação pautada no respeito mútuo, comprovado pela assiduidade, pontualidade e compromisso dos alunos participantes dos minicursos e estagiários durante os encontros realizados. E, ainda, antes de encerrar a disciplina, analisamos juntos os desafios de, uma ação para fomentar uma nova realidade curricular, conforme lembra Tómas da SILVA(2001), para quem currículo é um espaço, um campo de produção e de criação de significados. Embora seja consciente de que a idéia dos minicursos é apenas uma gota de extensão universitária e não passa de um caminho alternativo, acredito que desta forma confere-se um novo significado ao Estágio Supervisionado. E saí ciente de que, apesar dos inúmeros desafios, houve um despertar histórico naquele momento em diferentes instituições da educação formal, e assim é possivel afirmar que: "Diante do muito que é preciso fazer para estreitar os laços entre a Universidade, a escola, e a comunidade, trabalhar com projeto de minicurso se afirmou como um caminho" (TIMBÓ, 2005, p. 82), que faz da História tempo de possibilidades e não de determinismo.

A cada semestre, em torno de 10 (dez) escolas públicas, de modo especial, da periferia de Fortaleza, tornam-se parceiras da formação docente dos futuros historiadores-educadores do Curso de História da UECE.

No ano de 2004, primeiro semestre, houve os seguintes minicursos, conforme o quadro divulgado na época: 


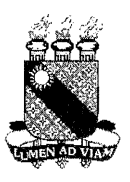

UNIVERSIDADE ESTADUAL DO CEARÁ

\section{CENTRO DE HUMANIDADES}

CURSO DE HISTÓRIA FONE: (0xx85) 2992661

CURSO RECONHECIDO EM 12/07/50 DECRETO 2837000

PROFESSORA: ISAÍDE BANDEIRA 99511740 isaidebs@bol.com.br

MINICURSOS - DISC.PRÁTICA DE ENSINO EM HISTÓRIA - NOITE/ 2004

\begin{tabular}{|c|c|c|c|}
\hline OR & EQUIPE/DISCIPLINA & TEMA DO MINICURSO & ESCOLA/ENDEREÇO \\
\hline 01 & $\begin{array}{l}\text { Edvaldo Rodriguês Mat. } 0641500 \\
\text { Fátima Regina Mat. } 0589231 \\
\text { Luiz Júlio Mat. } 0776097\end{array}$ & $\begin{array}{l}\text { "Riquezas do Ceará" } \\
\text { (Prática de Ensino II) } \\
18 \text { à 24/05/04 }\end{array}$ & $\begin{array}{l}\text { EEFM Anísio Teixeira- } \\
\text { Bairro: Pan Americano/Rodolfo Teófilo }\end{array}$ \\
\hline 02 & $\begin{array}{l}\text { Elineide Alves Mat. } 0641390 \\
\text { Mary Anne Holanda Mat. } 0686760\end{array}$ & $\begin{array}{l}\text { "A Ditadura Militar no Ceará" } \\
\text { (Prática de Ensino II) } \\
24 \text { à 28/05/04 }\end{array}$ & $\begin{array}{l}\text { EEFM Casimiro Montenegro } \\
\text { Av. dos Expedicionários, } 11360 \text {-Bairro: Itapery } \\
\text { Fone: } 4334926\end{array}$ \\
\hline 03 & $\begin{array}{l}\text { Ant. William Mat. } 0630715 \\
\text { Manoel Jarbas Mat. } 0641441 \\
\text { Thomas Ellery Mat. } 0410591\end{array}$ & $\begin{array}{l}\text { "Questão Indígena no Ceará" } \\
\text { (Prática de Ensino I) } \\
\text { 31/05/04 à 04/06/04 }\end{array}$ & $\begin{array}{l}\text { EEFM Arquiteto Rogério Fróes - Av. das } \\
\text { Graviolas, } \\
\text { 1000-Bairro: Cidade } 2000 \text { - } \\
\text { Fone: } 4338250\end{array}$ \\
\hline 04 & $\begin{array}{l}\text { Alyne Bezerra Mat. 0642504 } \\
\text { Anna Hilda Silva Mat. 0642438 } \\
\text { Paula Virginia Batista } \\
\text { Mat. } 0642771 \\
\end{array}$ & $\begin{array}{l}\text { "Ditadura Militar no Ceará" } \\
\text { (Prática de Ensino II) } \\
14 \text { à 18/06/04 }\end{array}$ & $\begin{array}{l}\text { EEFM Hermenegildo Firmeza - Bairro: Vila } \\
\text { Pery } \\
\text { Próximo à Cônego de Castro }\end{array}$ \\
\hline 05 & $\begin{array}{l}\text { Ant. Vagner Freire Mat. } 0641193 \\
\text { Cleide de Sousa Mat. } 0641336 \\
\text { Herbênia Monte Mat. } 0641368 \\
\end{array}$ & $\begin{array}{l}\text { "Ceará: História, diversidade cultural e riquezas" } \\
\text { (Prática de Ensino I) } \\
14 \text { à 18/06/04 }\end{array}$ & $\begin{array}{l}\text { EEFM Noel Hügnen de Oliveira- } \\
\text { Bairro: João XXIII } \\
\text { Próximo à Av. Pontes Vieira } \\
\end{array}$ \\
\hline 06 & $\begin{array}{l}\text { Ma. Idelzuite Coutinho Mat. } 0641220 \\
\text { Michel Holanda Mat. } 0641343 \\
\text { Rosa Ma. Ferreira } \\
\text { Mat. 0641480 }\end{array}$ & $\begin{array}{l}\text { "Patativa do Assaré: um símbolo do Ceará" } \\
\text { (Prática de Ensino I) } \\
14 \text { à 18/06/04 }\end{array}$ & $\begin{array}{l}\text { EEFM Juarez Távora- } \\
\text { Rua Joaquim Bastos, } 747 \\
\text { Bairro: Fátima Fone: } 2272939\end{array}$ \\
\hline 07 & $\begin{array}{l}\text { Marcizo Veimar Mat. } 0686571 \\
\text { Mary Anne Holanda } \\
\text { Mat. } 0686760\end{array}$ & $\begin{array}{l}\text { "Ditadura Militar no Ceará: um fato para } \\
\text { pensar" } \\
\text { (Prática de Ensino I) } \\
21 \text { à 25/06/04 }\end{array}$ & $\begin{array}{l}\text { EEFM João Matos - } \\
\text { Bairro: Montese -Próximo ao Hospital da } \\
\text { Criança }\end{array}$ \\
\hline 08 & $\begin{array}{l}\text { Carlos Roberto Bastos Mat. } 0620076 \\
\text { David Paiva Mat. } 0560869 \\
\text { Elaine Lima Mat. } 0725435 \\
\end{array}$ & $\begin{array}{l}\text { "História dos Pontos Turísticos do Ceará" } \\
\text { (Prática de Ensino I) } \\
23 \text { à 26/06/04 }\end{array}$ & $\begin{array}{l}\text { EEFM Paróquia da Paz- } \\
\text { Bairro: Aldeota } \\
\text { Próximo ao Shopping Avenida }\end{array}$ \\
\hline 09 & $\begin{array}{l}\text { Niedja Portugal Mat. } 0642361 \\
\text { Rodrigo Capistrano Mat. } 0478267\end{array}$ & $\begin{array}{l}\text { "Linha e Entrelinhas do Vestibular: Brasil e } \\
\text { Ceará na República" } \\
\text { (Prática de Ensino II) } \\
\text { sábados de junho/manhã }\end{array}$ & $\begin{array}{l}\text { CAIC-Centro de apoio Integrado-R, } \\
\text { Sargento Barbosa s/n-Bairro: Granja } \\
\text { Lisboa/BomJardim }\end{array}$ \\
\hline 10 & $\begin{array}{l}\text { David Bosford Mat. } 0620005 \\
\text { Elaine Silva Mat. } 0725435 \\
\text { Cícero 'Túlio Mat. } 0561386\end{array}$ & $\begin{array}{l}\text { "Demócrito Rocha: uma personalidade } \\
\text { cearense" } \\
\text { (Prática de Ensino I) } \\
21 \text { à 25/06/04 }\end{array}$ & $\begin{array}{l}\text { EEFM Fernandes Távora- } \\
\text { R. Góias, 151-Bairro: Demócrito Rocha Teófilo }\end{array}$ \\
\hline
\end{tabular}

\section{CONTAMOS COM SUA VISITA!!!}

A Universidade, naquele semestre, pôde chegar a diferentes bairros da periferia de Fortaleza. É uma questão social! E para melhor salientar o trabalho desenvolvido pelos estagiários, comentarei sobre três dos minicursos há pouco citados: 
$1^{\circ}$ "Arte e Cultura popular do Ceará" - elaborado pelo estagiários, da prática de Ensino II, Edvaldo Rodriguês, Fátima Regina e Luiz Júlio; realizado na Escola Anísio Teixeira (Bairro: Pan Americano - Fortaleza/CE), durante as segundas e quartas, à noite, do mês de maio. Teve como objetivos: reconhecer, valorizar e preservar o patrimônio histórico local, e, assim, conscientizar-se da importância da cultura cearense para construção da cidadania; metodologicamente, trabalharam com aulas expositivas que primam pela problematização, debates, projeção de imagens, músicas, como exemplo: "Canto das três raças" (Paulo César Pinheiro), dinâmicas e oficina de artesanato, principalmente com a produção de xilogravuras, prosa e verso.

Este posicionamento indagativo, pautado na pedagogia do diálogo, favorece aos(as) alunos(as) a oportunidade de participarem de forma atuante nas aulas. As perguntas variam de complexidade, conforme o nível escolar e cognitivo de cada turma, considerando sua realidade sócio-histórica, mas sem ser superficial nos assuntos trabalhados e nem caindo no "presentismo", que não favorece a compreensão da História como processo relacional entre múltiplos tempos e espaços.

É possivel salientar um comentário de um estagiário desse minicurso na avaliação do trabalho desenvolvido:

0 minicurso para quem não tem a experiência de sala de aula é sempre muito importante e válido. É pena constatar, com tristeza é claro, que o nível baixo dos alunos de ensino médio da escola pública, como denunciam as pesquisas, é uma realidade. (Júlio César)

$2^{\circ}$ - "A Ditadura Militar no Ceará" - organizado pelas estagiárias da Prática de Ensino II Elineide Alves e Mary Anne Holanda. Realizado na Escola Casimiro Montenegro (Bairro: Itapery - Fortaleza-/CE), na última semana do mês de maio/ 2004. Objetivou compreender os fatos ocorridos no período da ditadura militar e a influência destes na vida do povo cearense. Refletir, ainda, sobre os princípios da democracia e da liberdade. Assim, utilizaram como metodologia: apresentação de filmes, como "Barra 68: sem perder a ternura" e "0 que é isso companheiro"; confecção de painéis com materias de jornais e imagens sobre a ditadura; leitura e debate de artigos, pautados em uma relação dialógica. 
Neste caso, é importante salientar que uma das funções fundamentais que cabe ao(a) professor(a) de História é articular o patrimônio cultural da humanidade e o universo cultural dos(das) alunos(as), pois, conforme salientam Jaime e Carla PINSKY, "o passado deve ser interrogado a partir de questões que nos inquietam no presente..." (2003, p.23), sendo importante, portanto, não cair no vício de ensinar uma História chamada "crítica" porém sem base, ou seja, sem fatos (sem conteúdo!), “...em que o conhecimento histórico se transforma numa sabedoria de almanaque mal digerida, em que acontecimentos, instituições, e movimentos ocorrem do nada para 0 nada." (Idem, p. 35)

$\mathrm{Na}$ avaliação, alguns alunos inscritos no minicurso destacaram por escrito," ... o curso deveria ter a $2^{2}, 3^{2}, 4^{2}$ e $5^{2}$ remeça." E outro destaca quanto as estagiárias: "... uma capacidade excelente de dar aulas, pois fazem a gente sentir vontade de aprender, e são competentes." A vice-diretora da escola por meio de um ofício expedido para a Universidade salientou: "A realização de trabalhos desta natureza e que prestigiam o convívio dos indivíduos e a socialização do conhecimento, serão sempre bem vindos." (Luiza Menezes). E uma das estagiárias comentou:

Para mim foi um mérito muito grande, de oferecer nesses cinco dias um pouco de conhecimento para esses alunos e de ver o interesse que cada um demonstrava pelo assunto. Apesar de ter ficado muito nervosa no primeiro dia, pois nunca ensinei, mas consegui ... com a ajuda e colaboração de cada aluno (Mary Anne).

$3^{\circ}$ - "Patativa do Assaré: um símbolo do Ceará" - elaborado pelos estagiários da Prática de Ensino I Idelzuite Coutinho, Michel Holanda e Rosa Ferreira. Executado na Escola Juarez Távora (Bairro: Nossa Senhora de Fátima - Fortaleza/CE), durante a segunda semana do mês de junho/2004. 0 objetivo foi de mostrar a biografia de um artista da cultura popular do Ceará, Patativa do Assaré, e analisar algumas de suas poesias. Os Parâmetros Curriculares Nacionais do ensino fundamental indicam como um dos objetivos do ensino de História "valorizar o patrimônio sociocultural e respeitar a diversidade social, considerando critérios éticos."(BRASIL, 1998, p.43)

Para melhor desenvolver o minicurso, trabalharam com mostra de 
documentários sobre Patativa, leitura, debate e dramatização de suas poesias; e ainda contaram com a participação especial de um cantor e compositor da terra, Pingo de Fortaleza, que conviveu e compôs com Patativa do Assaré algumas letras.

De acordo com a avaliação feita pelos estagiários frente ao que foi vivido no decorrer do minicurso, é válido destacar dois comentários:

A experiência das aula práticas sob o formato de minicurso, foi muito gratificante, não apenas pelo inusitado, mas principalmente por tornar-se uma confirmação de minha opção por uma curso de licenciatura... (Idelzuite Coutinho).

... pude comprovar na prática parte da teoria discutida na Universidade. Bem diferente do estágio de observação participante, onde eu participava só através de comentários nas aulas, mas não como responsável pela sala de aula, (...] Dessa vez a responsabilidade era nossa (da equipe]. Sendo que eu nunca tinha dado uma aula em um escola antes. (Michel Holanda).

Convém salientar que 0 ensino-aprendizagem na educação histórica precisa estar voltado para a construção da cidadania efetiva. Nesta perspectiva, é imprescindível problematizar o que será ensinado, fazer indagações que estimulem os(as) alunos(as) a pensarem de forma reflexiva e favoreçam uma postura transformadora diante da sociedade, como protagonistas da cena histórica que se processa a cada dia, e não como figurantes. 0 ensino de História, assim comprometido, viabiliza a compreensão da luta permanente e necessária na concretização dos direitos inalienáveis do ser humano.

Uma das críicicas com relação aos minicursos é quanto à realidade da sala de aula ser algo forjado, já que os alunos das escolas que se inscrevem para participar dos minicursos têm liberdade de optar por estar ou não ali, diferente do cotidiano da sala de aula convencional, onde em geral, o alunado não tem escolha e assim está mais propício à indisciplina. Não posso negar que o público discente dos minicursos é auto-selecionado, já que se parte do pressuposto de que só se inscreve quem quer de fato participar. Posso afirmar, contudo, frente às diferentes supervisões de acompanhamento que já realizei aos minicursos, que, ao se formar uma sala de aula, ela terá todos os ingredientes de qualquer outra sala, pois terá alunos com diferentes bagagens culturais, além de expectativas, dúvidas e desafios, ou seja, o 
formando terá que lidar com variados aspectos de ordem teorico-metodológica. Como destaca Maria SCHMIDT, "Na sala de aula se realiza um espetáculo cheio de vida e de sobressaltos." (1996, p. 56)

No decorrer da execução do minicurso, portanto, caberá à equipe de estagiários viver e buscar opções para vencer os possíveis obstáculos da sala de aula, mediante uma postura pedagógica condizente, fazendo uso das diferentes ferramentas adquiridas no decorrer do curso de licenciatura. Afinal, uma sala de aula tem encantos e mistérios imprevisíveis, como anota o professor SOUSA NETO (S/D), da UFC: "A aula, toda ela, todas elas, devem ser um ato de amor, uma dança, (...), um ato político, uma manifestação de indignação contra as injustiças."

Outra crítica quanto aos minicursos diz respeito aos diferentes materiais utilizados na metodologia de aula dos estagiários. Alguns salientam que não condizem com a realidade das escolas públicas. Será? De acordo com minha experiência nas supervisões dos minicursos, na maioria das escolas, principalmente as de ensino fundamental (em virtude da verba do FUNDEF Fundo de Desenvolvimento do Ensino Fundamental), há: televisor, vídeo, DVD, conjunto de som, retroprojetor e até episcópio. Este material, porém, quase não é usado pela maioria dos professores das escola e alguns desconhecem que estes materiais estão à disposição para favorecer suas aulas. E esses, em geral, são os recursos mais utilizados pelos estagiários para desenvolver uma aula com o prazer de ensinar e aprender.

Agora, é claro que, outros materiais também necessários, como transparências, fitas (alugadas), CDs e DVDs ficam por conta da equipe de estagiários. Afinal, é um investimento no seu trabalho, mas reconheço que não temos o direito de exigir esse "sacrifício" de todos os professores no cotidiano de seu ofício. Infelizmente essa constatação não é uma exceção! Por conseguinte, até que ponto é legítimo criticar aquele professor que se limita a lousa e giz/ pincel? Será que não há, porém, possibilidade de reverter essa situação? A necessidade de material de consumo é apontada às gestões escolares, que 0 solicitam aos órgãos competentes das secretarias de educação do Município de Fortaleza e/ou do Estado?

Fica, ainda, por conta do professor da disciplina o custo com o deslocamento para as visitas de acompanhamento nas escolas, apesar de ser considerado, pela própria Pró-Reitoria de Extensão, um trabalho de extensão universitária. 
É inegável que esta proposta alternativa de vivenciar o Estágio Supervisionado origina incertezas(por isso, algumas críticas), e exige uma boa dose de dedicação e empenho, principalmente dos estagiários e do(a) professor(a) da disciplina, pois é preciso uma sensibilização de todos para acreditar que é possível fazer diferente em prol de uma formação de qualidade de fato para todos. Enfim, como destaca NIKITIUK (1996, p.10), "só uma coisa é certa: é preciso buscar."

Tendo o trabalho com projetos como base ensinar e aprender, muito mais do que cumprir os créditos acadêmicos, o minicurso é uma ação que desafia os obstáculos e estimula a reflexão sobre o ensino de História tecido na sala de aula. Assim, pensar o ensino de História como objeto de pesquisa é fundamental para uma ação diferente no Estágio Supervisionado, para além do preenchimento de fichas e confecção de relatórios burocráticos. Ressalto a necessidade de contribuir com as inúmeras escolas que são laboratórios para os estagiários dos cursos de licenciaturas., portanto, o minicurso mostra-se como um trabalho social, feito em parceria, numa clara relação dialógica entre Universidade e comunidade.

De acordo com Sandra CORAZZA ( 1997, p. 140), é preciso "experienciar durante 0 trabalho de formação docente, a positividade e a produtividade críticas de práticas pedagógicas alternativas, que capacitem o futuro professor a planejar e desenvolver currículos alternativos e contra-hegemônicos." Só assim será possível a constituição de uma educação de qualidade concreta para todos. Como lembra Pedro DEMO (1994, p.40), a "educação qualitativa é precisamente aquela que constrói a capacidade de questionar, para melhor agir." Neste caso, o aluno precisa ser visto como capaz de questionar, em vez de objeto passivo "pronto" para receber a transmissão do conhecimento do professor, ao estilo da chamada "educação bancária". Ele deve ser motivado a perguntar, pois, assim, conforme lembra Demo, vai construindo o perfil de um sujeito histórico capaz de conceber e fazer o projeto próprio de desenvolvimento, na compreensão de que ensinar História, ou qualquer outra disciplina, não é mero treinamento da memória, mas antes, formar capacidade crítico- reflexiva.

Por isso é importante nos cursos de Licenciatura em História ensejar espaços para ampliar debates sobre as diferentes práticas que ocorrem no ensino de História promovido nos variados níveis de ensino e escola, e, ainda, que a Prática de Ensino possa estar presente no docorrer no decorrer do Curso de 
História e não no último ano de licenciatura, para que a História ensinada possa ser um convite e um desafio para intervenção social de fato, a partir da formação da consciência histórica. Por isso as políticas de formação docente precisam ter como pressuposto a redefinição das concepções de educação, História e prática pedagógica.

0 estudo de História fará seu papel de intervenção social na construção da cidadania efetiva, quando favorecer aos milhares de estudantes, em todos os níveis de ensino, a percepção do processo histórico, de que a realidade é construída por diferentes atores sociais nos diversos tempos e espaços, e que é possível transformá-la. Portanto, não há uma História a ser apreendida e reproduzida, por exemplo, nas provas bimestrais, mas Histórias feitas de experiências humanas, o que não significa negar datas e fatos mas compreendêlos em um contexto histórico.

Enfim, fazer diferente da perspectiva tradicional no Ensino de História é urgente e remete à discussão sobre a formação de professores; não só a chamada inicial mas também uma formação continuada (em serviço), são ambas imprescindíveis. É importante esclarecer, entretanto, que diante das precárias condições de muitas escolas e salários aviltantes ${ }^{6}$, é preciso que os professores se mobilizem nas esferas competentes e não usem desse discurso para fazer mal sua função profissional, embora uma educação de qualidade não dependa só do professor, mas este desempenha um papel fundamental no processo de ensino-aprendizagem.

É preciso que se considere, portanto, a formação docente como parte do metier do historiador que trabalha no seu cotidiano com os conceitos, documentos e, sobretudo, com a produção do conhecimento pautado nas experiências humanas, o que requer, além do estímulo à pesquisa acadêmica e professores comprometidos, atividades extra-curriculares, como participação em congressos, seminários e a realização de projetos sociais de extensão universitária, por exemplo, no mínimo para um real ganho de qualidade no curso de História, no tocante à licenciatura.

\footnotetext{
6 ParaJoana Neves um dos principais fatores que interfere na exígua formação do professoré a questão salarial, que faz com que improvisações substituam a profissionalização, assim salienta a urgência de um política educacional que promova a profissão do magistério com: formação adequada, condições estruturais e materiais necessários, tempo integral para se dedicar a carreira e uma política salarial condizente. (NEVES, 2000.)
} 
Aindaépor demais relevante que os Cursos de História (licenciatura), abordem de forma consistente uma reflexão sobre currículo, pois entre 0 oficial $\mathrm{e}$ real há um mundo a ser pesquisado. Nesta perspectiva, a professora Margarida OLIVEIRA (2002) defende a urgência da percepção do ensino de História como objeto de pesquisa, para que não só a externalidade (leis, programas, livros didáticos) da sala de aula seja estudada, mas também a internalidade (como professores e alunos se relacionam com a externalidade imposta), para que uma ação (trans)formadora da consciência crítico-reflexiva possa de fato acontecer nas aulas de História.

E conforme sintetiza Paulo FREIRE (1992, p. 25), em Pedagogia da Esperança: "Hoje a gente está começando a viver um nova maneira de ser históricos." Isto requer participar de forma ativa de todos os espaços possíveis para fazer diferente no ensino de História, numa perspectiva de compreensão e transformação social, independentemente do nível de ensino e das amarras burocráticas. Viver a experiência de minicursos, portanto, é ter a oportunidade não só de praticar uma série de teorias adquiridas no decorrer do curso de licenciatura, mas, principalmente, burilar uma postura educacional, tão necessária nas diferentes escolhas do exercício docente no cotidiano e contribuir para um ensino de História dinâmico e reflexivo.

\section{Referências}

BRASIL. Ministério da Educação. Secretaria de Educação Fundamental. Parâmetros Curriculares Nacionais: história. Brasília: MEC/SEF, 1998.

Secretaria de Educação Média e Tecnológica. Parâmetros Curriculares Nacionais: ensino médio. Ciências Humanas e suas Tecnologias. Brasilia: MEC, 1999.

CERTEAU, Micheu de. A Invenção do Cotidiano: 1. Artes de Fazer. Tradução de Ephraim Frerreira Alves. Petrópolis, RJ: Vozes, 1994.

CORAZZA, Sandra Mara. "Planejamento de Ensino Como Estratégia de Polííica Cultural." In.: MOREIRA, Antônio Flávio Barbosa. (org.) Currículo: Questões Atuais. Campinas, São Paulo: Papirus, 1997. DEMO, Pedro. Educação e Qualidade. Campinas, São Paulo: Papirus, 1994.

CRUZ NET0, Otávio. 0 trabalho de campo como descoberta e criação. In.: Pesquisa Social: teoria, método e criatividade. Maria Cecília de Souza Minayo (org). Petrópolis, RJ: Vozes, 1994. 
FONSECA, Selva Guimarães. Didática e Prática de Ensino. São Paulo: Papirus, 2003.

FREIRE, Paulo. Pedagogia da Esperança: Um Reencontro com a Pedagogia do Oprimido. 10ª ed. São Paulo: Paz e Terra, 1992. Pedagogia da Autonomia. $7^{a}$ edição. São Paulo: Paz e Terra, 1996.

HERNÁNDEZ, Fernando. Transgressão e Mudança na Educação: os Projetos de Trabalho. Tradução de Jussara Haubert. Porto Alegre: Art Med, 1998.

LIMA, Maria Socorro Lucena. A Hora da Prática: reflexões sobre o estágio supervisionado. Fortaleza: Editora Demócrito Rocha, 2001.

NEVES, Joana. "Perspectivas do Ensino de História: Desafios Político Educacionais e Historiográficos." In.: OLVEIRA, Margarida Maria Dias de. Contra o Consenso: $L D B$, DCN, PCN e Reformas no Ensino. João Pessoa: ANPUH/PB - Editora Sal da Terra, 2000.

NIKITIUK, Sônia L. (org.) Repensando o Ensino de História. São Paulo: Cortez, 1996.

OLIVEIRA, Margarida Maria Dias de. "0 Ensino de História como Objeto de Pesquisa." In.: SAECULUM: Revista de História - No. 6/7 Jan. Dez. 2000/2001 - João Pessoa: ed. Universitária/UFPB, 2002.

PINSKY, Carla e PINSKY, Jaime. "0 que e como Ensinar - Por uma História Prazerosa e Conseqüente." In.: KARNAL, Leandro (org.). História na Sala de Aula: Conceitos, Práticas e Propostas. São Paulo: Contexto, 2003.

SCHMIDT, Maria Auxiliadora. Saber Histórico na Sala de Aula. In.: ANAIS. III Encontro Perspectivas do Ensino de História. Curitiba: Aos 4 ventos, 1999.

SILVA, Tomaz Tadeu da. O Currículo como Fetiche: a poética e a política do texto curricular. $2^{a}$ ed. Belo Horizonte: Autêntica, 2001.

SOUSA NETO, Manoel Fernandes de. "A Aula". Professor d Departamento de Geografia da Universidade Federal do Ceará. Mimeo;

TIMBÓ, Isaíde Bandeira. "Aprendendo a ensinar". In.: Revista Nossa História. Ano 2 no. 16. Rio de Janeiro: Vera Cruz, fev. 2005. 